University of Nebraska - Lincoln

DigitalCommons@University of Nebraska - Lincoln

\title{
Regional Variation in Total Cost per Radical Prostatectomy in the Healthcare Cost and Utilization Project Nationwide Inpatient Sample Database
}

\author{
Danil V. Makarov \\ Yale University School of Medicine, danil.makarov@nyumc.org \\ Stacy Loeb \\ The Johns Hopkins Medical Institutions, stacyloeb@gmail.com \\ Adam B. Landman \\ New Haven and Department of Veterans Affairs Connecticut Healthcare System \\ Matthew E. Nielsen \\ University of North Carolina School of Medicine \\ Cary P. Gross \\ Yale University School of Medicine, cary.gross@yale.edu \\ See next page for additional authors
}

Follow this and additional works at: https://digitalcommons.unl.edu/veterans

Makarov, Danil V.; Loeb, Stacy; Landman, Adam B.; Nielsen, Matthew E.; Gross, Cary P.; Leslie, Douglas L.; Penson, David F.; and Desai, Rani A., "Regional Variation in Total Cost per Radical Prostatectomy in the Healthcare Cost and Utilization Project Nationwide Inpatient Sample Database" (2010). U.S. Department of Veterans Affairs Staff Publications. 53.

https://digitalcommons.unl.edu/veterans/53

This Article is brought to you for free and open access by the U.S. Department of Veterans Affairs at DigitalCommons@University of Nebraska - Lincoln. It has been accepted for inclusion in U.S. Department of Veterans Affairs Staff Publications by an authorized administrator of DigitalCommons@University of Nebraska - Lincoln. 


\section{Authors}

Danil V. Makarov, Stacy Loeb, Adam B. Landman, Matthew E. Nielsen, Cary P. Gross, Douglas L. Leslie, David F. Penson, and Rani A. Desai 


\title{
Regional Variation in Total Cost per Radical Prostatectomy in the Healthcare Cost and Utilization Project Nationwide Inpatient Sample Database
}

\author{
Danil V. Makarov, * Stacy Loeb, Adam B. Landman, Matthew E. Nielsen, Cary P. Gross, \\ Douglas L. Leslie, David F. Penson and Rani A. Desai \\ From the Robert Wood Johnson Clinical Scholars Program (DVM, ABL, CPG, RAD), Sections of Urology (DVM) and Department of Emergency \\ Medicine (ABL), and Departments of Internal Medicine (CPG) and Psychiatry (RAD), School of Epidemiology and Public Health (RAD), Yale University \\ School of Medicine, New Haven and Department of Veterans Affairs Connecticut Healthcare System (DVM, ABL, RAD), West Haven, \\ Connecticut, The Brady Urological Institute, The Johns Hopkins Medical Institutions (SL), Baltimore, Maryland, Section of Urology, University of \\ North Carolina School of Medicine (MEN), Chapel Hill, North Carolina, Center for Health Economics and Policy Studies, Medical University of South \\ Carolina (DLL), Charleston, South Carolina, and Department of Urologic Surgery, Vanderbilt University Medical Center (DFP), Nashville, Tennessee
}

\section{Abbreviations and Acronyms \\ $\mathrm{CaP}=$ prostate cancer \\ $\mathrm{CMS}=$ Centers for Medicare and Medicaid Services \\ HCUP $=$ Healthcare Cost and Utilization Project \\ NIS = Nationwide Inpatient Sample \\ $\mathrm{RP}=$ radical prostatectomy \\ $\mathrm{TC}=$ total cost}

Submitted for publication July 20, 2009 . Supported by the Veterans Health Administration and The Robert Wood Johnson Foundation.

* Correspondence and requests for reprints: Yale University School of Medicine, P. O. Box 208088, 333 Cedar St., IE-61 SHM, New Haven, Connecticut 06520 (telephone: 203-785-2465; FAX: 203-785-3461; e-mail: danil.makarov@yale.edu).

Supplementary material for this article can be obtained at http://rwjcsp.yale.edu/files/scholar/ Table\%201.pdf and http://rwjcsp.yale.edu/files/ scholar/Table\%202.pdf.

Purpose: Surgical treatment for prostate cancer represents a large national health care expenditure. We determined whether state level variation in the cost of radical prostatectomy exists and whether we could explain this variation by adjusting for covariates associated with cost.

Materials and Methods: Using the 2004 Healthcare Cost and Utilization Project National Inpatient Sample of 7,978,041 patients we identified 9,917 who were 40 years old or older with a diagnosis of prostate cancer who underwent radical prostatectomy without cystectomy. We used linear regression to examine state level regional variation in radical prostatectomy costs, controlling for the local area wage index, patient demographics, case mix and hospital characteristics. Results: The mean \pm SD unadjusted cost was $\$ 9,112 \pm \$ 4,434$ (range $\$ 2,001$ to $\$ 49,922)$. The unadjusted mean cost ranged from $\$ 12,490$ in California to $\$ 4,650$ in Utah, each significantly different from the mean of $\$ 8,903$ in the median state, Washington $(\mathrm{p}<0.0001)$. After adjusting for all potential confounders total cost was highest in Colorado and lowest in New Jersey, which were significantly different from the median, Washington $(\$ 10,750$ and $\$ 5,899$, respectively, vs $\$ 8,641, \mathrm{p}<0.0001)$. The model explained $85.9 \%$ of the variance with regional variation accounting for the greatest incremental proportion of variance $(35.1 \%)$ and case mix variables accounting for an incremental $32.3 \%$.

Conclusions: The total cost of radical prostatectomy varies significantly across states. Controlling for known total cost determinants did not completely explain these differences but altered ordinal cost relationships among states. Cost variation suggests inefficiencies in the health care market. Additional studies are needed to determine whether these variations in total cost translate into differences in quality or outcome and how they may be translated into useful policy measures.

Key Words: prostatic neoplasms, prostatectomy, health policy, small-area analysis, costs and cost analysis

Prostate cancer is the most commonly diagnosed noncutaneous malignancy in American men with approximately 186,320 incident cases in $2008 .{ }^{1}$ The total annual national expenditure on
$\mathrm{CaP}$ in the United States is high with estimates ranging between $\$ 1.72$ billion $^{2}$ and $\$ 4.75$ billion $^{3}$ annually according to 1990 costs. ${ }^{4}$ The cost burden to taxpayers is also substantial 
The Journal of Urology, Volume 183, Issue 4, April 2010, Pages 1504-1509

with $\$ 927$ million spent on $\mathrm{CaP}$ care for Medicare beneficiaries in $2001 .{ }^{5}$ Approximately $48 \%$ of spending on $\mathrm{CaP}$ treatment is associated with inpatient care, of which a large fraction is attributable to surgery. ${ }^{5}$

A Scandinavian randomized trial showed that $R P$ is superior to watchful waiting for $\mathrm{CaP} .{ }^{6-8}$ However, no randomized data exist on the comparative effectiveness of other available therapies, such as radiation or active surveillance etc. ${ }^{9,10}$ Accordingly therapeutic uncertainty has led to wide variation across American geographic areas in procedures used to treat $\mathrm{CaP}$, such as RP. ${ }^{11-13}$

However, the choice of therapy may be influenced not only by uncertainty about oncological superiority but also potentially by cost since patients are known to use less health care and less expensive health care when they are forced to pay for it out of pocket., ${ }^{44,15}$ Likewise providers of medical services produce less of any service as its cost increases. ${ }^{16,17}$ Since legal and payment mechanisms vary across states, we determined whether there is also state level variation in the cost of RP and whether we could explain this variation by adjusting for regional and patient level variables associated with cost.

\section{METHODS}

We used data available in 2009 from the 2004 HCUP-NIS (HCUP Databases. Healthcare Cost and Utilization Project [HCUP]. August 2009. Agency for Healthcare Research and Quality, Rockville, MD. www.hcup-us.ahrq.gov/nisoverview. jsp.), a $20 \%$ stratified sample of discharges from community hospitals representing the largest all payer, inpatient care database in the United States. Additional subfiles, the HCUP 2004 cost-to-charge ratio and hospital weights files, were merged with the core file to determine economic costs and hospital level covariates.

The database included data on 7,978,041 inpatient discharges from 2004. Since RP can only be performed once in any patient, we assumed that hospital discharges listing the $\mathrm{RP}$ procedure code identified unique patients. We limited data on the $3,264,088$ men to the $2,171,128$ who were 40 years old or older. We identified 11,254 patients with a diagnosis of $\mathrm{CaP}$ (ICD-9 code 185) who underwent RP (ICD-9 procedure code 60.5). We excluded from study 1,264 patients with missing data other than race and 17 who underwent simultaneous cystectomy (ICD-9 procedure codes 57.6, 57.7, 57.71 or 57.79) since this would indicate $\mathrm{CaP}$ diagnosed during treatment for bladder cancer. Based on analysis suggesting natural breaks at the low and high ends of the TC distribution we excluded 52 patients in whom TC was less than $\$ 2,000$ and 21 in whom TC was greater than $\$ 50,000$, leaving a final study sample of 9,917 .

The primary outcome variable was TC, determined by multiplying total charges by a hospital wide, all payer inpatient cost-to-charge ratio per hospital derived from CMS standardized hospital accounting reports. This ratio removes differences in markup used by hospitals to account for differences in payer mix, local competition and price strategy. ${ }^{18}$ Documentation, data and reports on cost estimation meth- ods are available from the Agency for Healthcare Research and Quality.

The primary independent variable was the state in which the hospital is located. The 2004 HCUP-NIS contains data from 37 states but no records from Hawaii were available of men undergoing $\mathrm{RP}$ and no cost-to-charge conversion data were available from Texas. The local area wage index developed for CMS reimbursement accounts for geographic variations in the price of hospital inputs endogenous to the local market. To allow for variable cost elasticity with respect to input prices we used this index as an explanatory variable. ${ }^{18}$ Covariates were classified into 3 classes, including patient demographics, case mix and hospital factors.

Demographics included race, urban-rural residence, median income in the patient residential ZIP Code ${ }^{\mathrm{TM}}$ and primary insurance payer. Race was classified as a 4-level variable comprising race and ethnicity (white, black, other or missing). White was the reference group. Other included Hispanic, Asian or Pacific Islander, Native American or other patients. Urban-rural residence was a 4-level variable describing county of residence, including large metropolitan (1,000,000 or more residents), small metropolitan (fewer than 1,000,000 residents) and micropolitan or nonurban (reference). Quartile classification of the estimated median household income in the patient ZIP Code was defined as $\$ 1$ to $\$ 35,999, \$ 36,000$ to $\$ 44,999, \$ 45,000$ to $\$ 58,999$, or $\$ 59,000$ or greater with the lowest income serving as the reference. Primary insurance payer was coded as a 3-level variable, including private insurance; Medicare or Medicaid; or self-pay, no charge or other payer. Private insurance was the reference.

Case mix included the continuous variables age in years, length of stay in days and number of procedures (maximum 15) as well as the 2 categorical variables alive (reference) or dead at hospital discharge, and a comorbidity score. Using the updated method of Elixhauser et $\mathrm{al}^{19}$ we determined the presence or absence of ICD-9 codes corresponding to any of 29 comorbidity measures according to HCUP-NIS (HCUP Databases. Healthcare Cost and Utilization Project [HCUP]. August 2009. Agency for Healthcare Research and Quality, Rockville, MD. www.hcup-us.ahrq.gov/nisoverview.jsp.). They were summed and grouped into the categories of 0,1 to 2 , or 3 or greater comorbidities. Hospital characteristics were bed size, designated by HCUP as small, medium or large based on the number of beds specific to the hospital location and teaching status. Ownership/control was stratified as public, voluntary (reference) and proprietary when a hospital and region were sufficiently large. In smaller strata public and private were combined with voluntary and proprietary hospitals comprising an individual private category. A separate category was created when no stratification was advisable due to limited hospital numbers according to HCUP-NIS. Teaching status was binary, including teaching (reference) or nonteaching. Urban-rural location, coded as rural vs urban (reference), was defined by Core Based Statistical Area codes.

Bivariate association between each covariate and TC was assessed by simple linear regression for continuous variables and ANOVA for categorical variables. Unadjusted mean TCs were calculated for each level of the categorical variables. The slope (change in TC per unit 
The Journal of Urology, Volume 183, Issue 4, April 2010, Pages 1504-1509

change in the independent variable) was calculated for continuous variables.

Due to the skewed TC distribution we modeled logtransformed TC as the dependent variable in multivariable models. We accounted for clustering patients in hospitals using generalized estimation equation models. We initially performed unadjusted examination of state variation in TC and then controlled sequentially for the local area wage index, demographics, case mix and hospital characteristics to establish incremental improvements in model fit. Incremental fit was determined by calculating the incremental proportion of variance, comparing fractional differences in the [-2]log likelihood of successive models. All covariates were presumed to be important confounders and were kept in the model regardless of statistical significance. We performed smearing retransformation to determine the $\mathrm{TC}$ per discharge, adding half the variance of the model error to the fitted value of log TC before exponentiation. ${ }^{20}$ Ordinal relationships between the TC per discharge of the states were examined.

Statistical analysis was done using SAS® 9.1. We used ArcGIS® 9.3 geographic information system software to visualize the geographic variation of RP TC across states. Individual state cartographic boundary files were obtained from the United States Census Bureau. ${ }^{21}$ The mean unadjusted RP TC per state was categorized as significantly below the median, no different from the median or significantly above the median and indicated on the map by shading. A similar process was repeated to create a shaded map of the United States for mean adjusted RP TC.

\section{RESULTS}

Mean \pm SD patient age was $61.0 \pm 7.0$ years. Mean unadjusted TC was $\$ 9,112 \pm \$ 4,434$ (range $\$ 2,001$ to $\$ 49,923)$. Men spent an average of $2.9 \pm 1.7$ days in the hospital and underwent $2.2 \pm 0.9$ procedures. Eight men $(0.1 \%)$ died as inpatients. Of the study sample $58 \%$ were white, $29 \%$ had no race information available, $65 \%$ had private insurance, $48 \%$ lived in a large metropolitan area and $31 \%$ resided in a ZIP Code where the median annual income was greater than $\$ 59,000$. Massachusetts contributed the greatest number of patients (685 or 7\%). Of the patients $92 \%, 70 \%$ and $56 \%$ were treated at urban, large and teaching hospitals, respectively.

Unadjusted mean costs were based on simple, untransformed linear regression or ANOVA. Washington was selected as the referent since its costs remained at or near the median in all models. We discovered significant unadjusted statewide variation in TC. Compared with the mean TC in Washington the highest cost state was California and the lowest was Utah $(\$ 8,903$ vs $\$ 12,490$ and $\$ 4,650$, respectively, each $\mathrm{p}<0.0001$ ). All other covariates were significantly associated with TC except insurance coverage and patient age.

The table shows the results of the unadjusted model determining log-transformed TC, accounting for patients clustered at hospitals. Unadjusted means were
Log-transformed linear regression models with smearing retransformations

\begin{tabular}{|c|c|c|c|c|}
\hline \multirow[b]{2}{*}{ Hospital State } & \multicolumn{2}{|c|}{ Unadjusted } & \multicolumn{2}{|c|}{ Fully Adjusted } \\
\hline & Estimate (\$) & p Value & Estimate (\$) & $\mathrm{p}$ Value \\
\hline Colorado & 10,305 & 0.0003 & 10,751 & $<0.0001$ \\
\hline Minnesota & 12,041 & $<0.0001$ & 10,494 & $<0.0001$ \\
\hline Massachusetts & 11,694 & $<0.0001$ & 10,403 & $<0.0001$ \\
\hline Virginia & 10,124 & $<0.0001$ & 10,260 & $<0.0001$ \\
\hline Georgia & 9,211 & 0.3006 & 10,022 & $<0.0001$ \\
\hline Florida & 8,589 & 0.1256 & 9,638 & 0.0002 \\
\hline Vermont & 10,237 & 0.0476 & 9,552 & 0.0737 \\
\hline California & 11,943 & $<0.0001$ & 9,420 & 0.0063 \\
\hline Arkansas & 7,562 & $<0.0001$ & 9,240 & 0.0621 \\
\hline Nebraska & 10,496 & $<0.0001$ & 9,201 & 0.094 \\
\hline South Carolina & 8,950 & 0.9569 & 9,133 & 0.0787 \\
\hline New Hampshire & 11,594 & $<0.0001$ & 9,057 & 0.2838 \\
\hline Indiana & 11,114 & $<0.0001$ & 9,046 & 0.3557 \\
\hline West Virginia & 8,825 & 0.7731 & 9,010 & 0.359 \\
\hline Illinois & 9,261 & 0.2808 & 8,995 & 0.1317 \\
\hline Tennessee & 8,110 & 0.0003 & 8,988 & 0.1852 \\
\hline Kentucky & 7,306 & $<0.0001$ & 8,863 & 0.4385 \\
\hline Michigan & 9,364 & 0.1765 & 8,853 & 0.4202 \\
\hline Ohio & 8,334 & 0.0247 & 8,713 & 0.786 \\
\hline Missouri & 7,663 & $<0.0001$ & 8,669 & 0.9214 \\
\hline Washington & 8,965 & Referent & 8,642 & Referent \\
\hline Oregon & 9,340 & 0.2292 & 8,629 & 0.9558 \\
\hline North Carolina & 7,707 & $<0.0001$ & 8,536 & 0.6392 \\
\hline Arizona & 7,317 & $<0.0001$ & 8,152 & 0.0541 \\
\hline South Dakota & 8,496 & 0.2526 & 8,053 & 0.0892 \\
\hline Rhode Island & 9,139 & 0.6944 & 7,971 & 0.039 \\
\hline Maryland & 7,697 & $<0.0001$ & 7,748 & 0.0004 \\
\hline New York & 10,093 & 0.0002 & 7,597 & $<0.0001$ \\
\hline Wisconsin & 7,703 & $<0.0001$ & 7,518 & $<0.0001$ \\
\hline Kansas & 6,990 & $<0.0001$ & 7,428 & $<0.0001$ \\
\hline Nevada & 7,745 & 0.0008 & 7,257 & 0.786 \\
\hline lowa & 6,996 & $<0.0001$ & 7,174 & $<0.0001$ \\
\hline Connecticut & 8,373 & 0.1312 & 6,266 & $<0.0001$ \\
\hline Utah & 4,733 & $<0.0001$ & 6,021 & $<0.0001$ \\
\hline New Jersey & 7,572 & $<0.0001$ & 5,899 & $<0.0001$ \\
\hline
\end{tabular}

calculated using smearing retransformation. Adjusting for covariate groups, including local area wage index (cost of living), demographics (urban/rural residence, race, median income quartile and primary insurance), case mix (length of stay, patient age, number of comorbidities, number of procedures and in-hospital survival) and hospital characteristics (ownership, bed size, teaching status and urban/rural location), together explained $85.9 \%$ of the variance in $\mathrm{TC}(5.6 \%$, $4.1 \%, 32.3 \%$ and $8.7 \%$ incremental proportion of variance, respectively). The unadjusted model alone regressing log-transformed TC on hospital state explained $35.1 \%$ of the variance.

All covariates were considered potential confounders and included in the model, although insurance status and age were not significantly associated with TC. In the fully adjusted model with Washington as the reference (mean cost $\$ 8,642$ ) the highest cost state was Colorado and the lowest was New Jersey $(\$ 10,751$ and $\$ 5,899$, respectively, each significantly different from the median, $\mathrm{p}<0.0001$ ). We then rank ordered the states by TC 
The Journal of Urology, Volume 183, Issue 4, April 2010, Pages 1504-1509

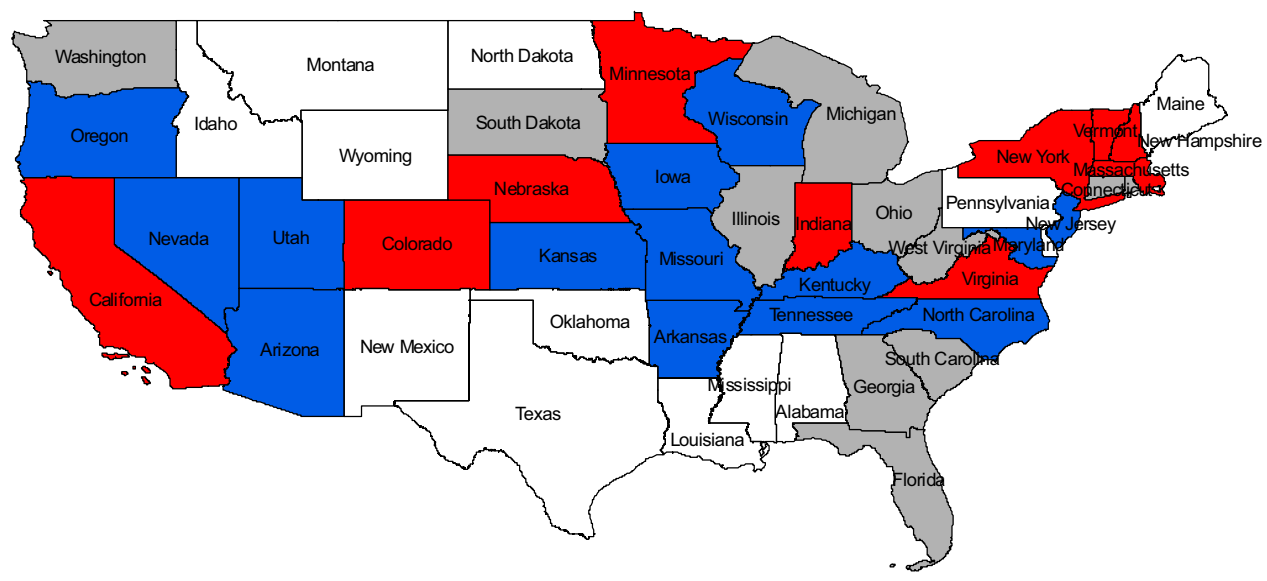

Figure 1. Mean unadjusted RP TC. White areas indicate not reporting. Blue areas indicate less than $\$ 8,400$ and below median ( $p<0.05$ ). Gray areas indicate $\$ 8,401$ to $\$ 10,000$ and no different than median ( $p \geq 0.05$ ). Red areas indicate greater than $\$ 10,000$ and above median ( $\mathrm{p}<0.05)$.

and used geographic information system mapping to show the results of the unadjusted and fully adjusted models (figs. 1 and 2). Adjusting for all potential confounders did not eliminate regional variation in TC but altered ordinal TC relationships between several states.

\section{DISCUSSION}

Small area variations in resource input, service use and expenditure may reflect inequalities in patient care and uncertainty regarding treatment effectiveness among physicians. ${ }^{11} \mathrm{CaP}$ treatments are often considered in such analyses since there is little randomized evidence for the comparative survival advantage of 1 treatment over another. ${ }^{5,12,13,22}$ Considerable effort has been expended to explain these variations in practice, primarily focusing on the characteristics of physicians who order higher level care and the circumstances under which they practice. $^{23-25}$ Cost is an important determinate of procedure supply and demand. ${ }^{14-17}$ Despite this well recognized phenomenon, to our knowledge there are no data on geographic variation in the cost of urological procedures. We determined the existence of state level variation in the cost of $\mathrm{RP}$ and its persistence despite controlling for known cost determinates.

A fully adjusted model explained $85.9 \%$ of the variance in cost but significant state level variation in TC persisted. Hospital state explained the greatest incremental proportion of TC variance $(35.1 \%)$ while case mix, which reflects the actual amount and complexity of care received by an individual, accounted for $32.3 \%$. Other covariates, such as hos-

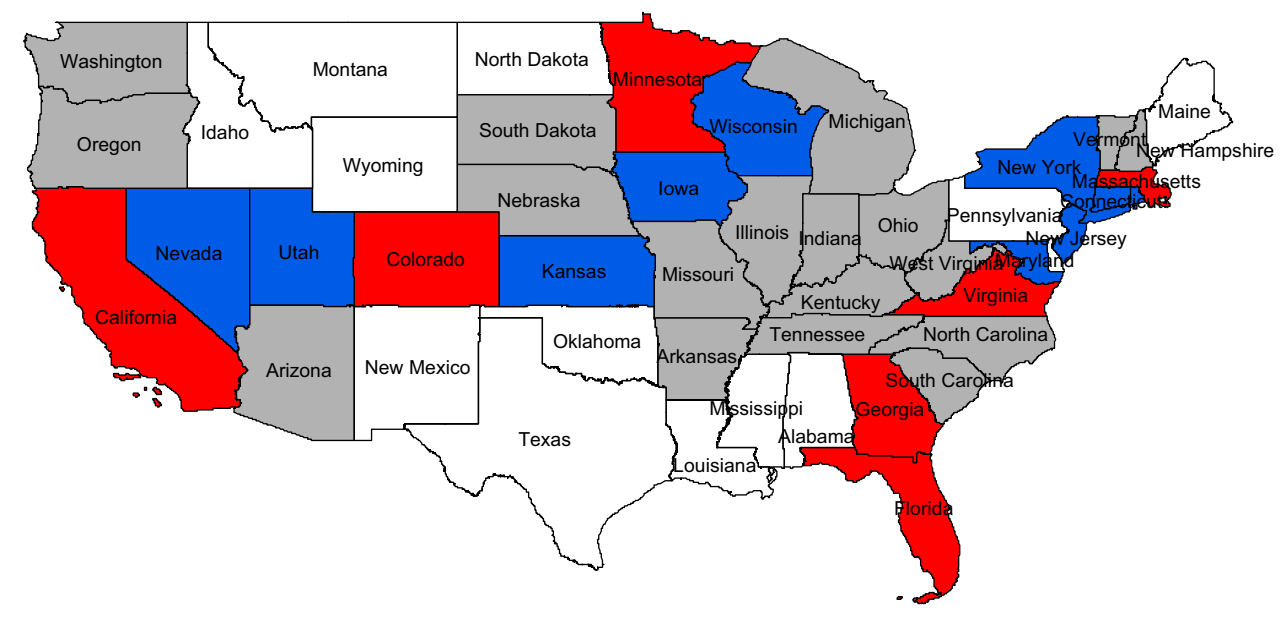

Figure 2. Mean adjusted RP TC. White areas indicate not reporting. Blue areas indicate less than $\$ 8,000$ and below median ( $p<0.05$ ). Gray areas indicate $\$ 8,001$ to $\$ 9,400$ and no different than median ( $p \geq 0.05)$. Red areas indicate greater than $\$ 9,401$ and above median $(\mathrm{p}<0.05)$. 
The Journal of Urology, Volume 183, Issue 4, April 2010, Pages 1504-1509

pital characteristics, local area wage index and demographics, accounted for a smaller proportion of the variance $(8.7 \%, 5.6 \%$ and $4.1 \%$, respectively).

A hypothesis explaining unadjusted state level variation in TC is that variation in $R P$ TC simply reflects state level variation in overall price for all local goods and services. This theory seemed plausible initially since northeastern and western states with well-known high costs of living were also those with the highest mean TC (fig. 1). However, controlling for the local area wage index accounted for only $2.7 \%$ of the variance in $\mathrm{TC}$ and did not alter the significance of the TC variation among states, suggesting it was not cost of living driving this phenomenon.

Adjusting for covariates associated with cost altered the ordinal relationship of TC between states. While some states retained their position relative to the median after adjustment, ie California had a high and New Jersey had low a TC before and after adjustment, other states changed in rank order. Adjustment tended to move southeastern and midwestern states to higher cost positions while northeastern states tended to move lower. The most dramatic example was New York, which had one of the highest TCs on unadjusted analysis but one of the lowest after adjustment.

There are several potential explanations for this phenomenon. States with higher unadjusted costs, which also tend to have a higher cost of living, may be under greater scrutiny from payers, as reported for individual hospitals with outlier payments to CMS and with anesthesia departments that use costly drugs. ${ }^{26,27}$ Such administrative scrutiny may force high cost providers to lower costs and operate under narrower margins. States with lower unadjusted costs may escape such pressure. Another possible explanation is that regions with higher prices may have higher population densities and treat more patients for all conditions. Higher statewide clinical volume may lead to economies of scale whose cost savings would only be appreciated after performing a fully adjusted analysis.

Our study has several limitations, including its crosssectional design, making it impossible to establish causality. We could not assess more specific details of care and complexity within individuals, which may better explain TC. This may be particularly important if there is regional variation in the stage at which $\mathrm{CaP}$ is diagnosed. Furthermore, NIS does not include outpatient data, precluding cost comparison between surgery and radiation therapy. Nor could we assess the rate of complications or the quality of care delivered.

Despite these limitations our analysis has a number of strengths. Data were derived from a nationally representative database including all types of patients and providers. Most regional variation data are based exclusively on CMS claims but our study benefits from including all payer data, allowing us to avoid the controversy associated with conclusions based only on CMS data. ${ }^{28}$ Most importantly NIS provides accurate data on the economic cost of therapy rather than the accounting cost or patient charge, allowing inferences to be made on the regional variation in resource consumption associated with $\mathrm{RP}$ without confounding from varying insurance reimbursement or other payment related factors. ${ }^{29}$

Perhaps the most important conclusion from these data is the caveat that unadjusted mean costs may be misleading. With almost $60,000 \mathrm{RPs}$ performed in 2000 and the number continuing to grow, an effort to decrease cost and/or improve quality could have an important impact on $\mathrm{CaP}$ care in the United States. ${ }^{5}$ The optimal targets for large-scale policy reform may not be the groups that appear to have the highest cost at first glance. A policy which simply cuts federal funding to a high cost state may backfire if that state is actually a low cost provider on adjusted analysis. In the debate over health care reform careful analysis of all factors contributing to TC is imperative. Without it we may unwittingly jeopardize access to and quality of care for many patients.

\section{CONCLUSIONS}

The RP TC varies significantly across states. Controlling for known determinants of medical care costs did not completely explain these differences but altered ordinal cost relationships between several states in informative ways. Differences in cost suggest inefficiency in the various health care markets. Additional studies are needed to determine whether these regional variations in TC translate into differences in quality of care or patient outcomes and how they may be translated into useful policy measures.

\section{REFERENCES}

1. Jemal A, Siegel R, Ward $E$ et al: Cancer statistics, 2008. CA Cancer J Clin 2008; 58: 71

2. Brown ML: The Economic Burden of Cancer. New York: Marcel Dekker 2005

3. Optenberg SA and Thompson IM: Economics of screening for carcinoma of the prostate. Urol Clin North Am 1990; 17: 719.
4. Saigal CS and Litwin MS: The economic costs of early stage prostate cancer. Pharmacoeconomics 2002; 20: 869 .

5. Penson DF and Chan JM: Prostate cancer. J Urol 2007; 177: 2020.

6. Holmberg L, Bill-Axelson A, Helgesen F et al: A randomized trial comparing radical prostatectomy with watchful waiting in early prostate cancer. N Engl J Med 2002; 347: 781.

7. Bill-Axelson A, Holmberg L, Ruutu M et al: Radical prostatectomy versus watchful waiting in early prostate cancer. N Engl J Med 2005; 352: 1977.

8. Bill-Axelson A, Holmberg L, Filen F et al: Radical prostatectomy versus watchful waiting in local- 
The Journal of Urology, Volume 183, Issue 4, April 2010, Pages 1504-1509

ized prostate cancer: the Scandinavian Prostate Cancer Group-4 randomized trial. J Natl Cancer Inst 2008; 100: 1144.

9. Albertsen PC, Hanley JA, Penson DF et al: 13Year outcomes following treatment for clinically localized prostate cancer in a population based cohort. J Urol 2007; 177: 932.

10. Penson DF, McLerran D, Feng $Z$ et al: 5-Year urinary and sexual outcomes after radical prostatectomy: results from the Prostate Cancer Outcomes Study. J Urol 2008; 179: S40.

11. Wennberg $\mathrm{J}$ and Gittelsohn A: Small area variations in health care delivery. Science 1973; 182: 1102.

12. Birkmeyer JD, Sharp SM, Finlayson SR et al: Variation profiles of common surgical procedures. Surgery 1998; 124: 917.

13. Lu-Yao GL, McLerran D, Wasson J et al: An assessment of radical prostatectomy. Time trends, geographic variation, and outcomes. The Prostate Patient Outcomes Research Team. JAMA 1993; 269: 2633.

14. Greenwald HP and Henke CJ: HMO membership, treatment, and mortality risk among prostatic cancer patients. Am J Public Health 1992; 82: 1099.

15. Manning WG, Newhouse JP, Duan N et al: Health insurance and the demand for medical care: evidence from a randomized experiment. Am Econ Rev 1987; 77: 251.

16. McGuire TG: Physician agency. In: Handbook of Health Economics. Edited by AJ Culyer and JP Newhouse. New York: Elsevier 2000.

17. Johnson-Lans S: A Health Economics Primer. Boston: Person/Addison Wesley 2006.

18. Friedman B, Jiang HJ, Elixhauser A et al: Hospital inpatient costs for adults with multiple chronic conditions. Med Care Res Rev 2006; 63: 327.

19. Elixhauser A, Steiner C, Harris DR et al: Comorbidity measures for use with administrative data. Med Care 1998; 36: 8.

20. Duan N: Smearing estimate: a nonparametric retransformation method. J Am Stat Assoc 1983; 78: 605.

21. Census 2000: State and State Equivalent Areas in ArcView Shapefile (.shp) Format. Washington, D. C.: United States Census Bureau 2009.
22. Lu-Yao GL, Potosky AL, Albertsen PC et al: Follow-up prostate cancer treatments after radical prostatectomy: a population-based study. J Natl Cancer Inst 1996; 88: 166.

23. O'Neill $L$ and Kuder $J$ : Explaining variation in physician practice patterns and their propensities to recommend services. Med Care Res Rev 2005; 62: 339 .

24. Sirovich B, Gallagher PM, Wennberg DE et al: Discretionary decision making by primary care physicians and the cost of U. S. health care. Health Aff (Millwood) 2008; 27: 813.

25. Nallamothu BK, Rogers MA, Chernew ME et al: Opening of specialty cardiac hospitals and use of coronary revascularization in Medicare beneficiaries. JAMA 2007; 297: 962.

26. Benko LB: On the lookout. CMS studies outlier billing practices. Mod Healthcare 2002; 32: 14.

27. Watcha MF and White PF: Economics of anesthetic practice. Anesthesiology 1997; 86: 1170.

28. Cooper RA: States with more health care spending have better-quality health care: lessons about Medicare. Health Aff (Millwood) 2009; 28: w103.

29. Finkler SA: The distinction between cost and charges. Ann Intern Med 1982; 96: 102.

\section{EDITORIAL COMMENT}

In industry a hallmark of good quality is minimal variation in the production process. These authors studied the production of RP. Their analysis shows wide variation in costs despite adjusting for medical case mix and local labor markets. Their analysis is based on data from 2004, a period preceding the widespread adoption of robotic prostatectomy.

Health care costs are a growing political issue. Physicians have historically defended the high cost of American health care by claiming the highest quality in the world. That does not explain the wide variations noted by these authors. Responsible health care reform requires urologists to participate in the development of care pathways that minimize resource consumption and collect better data on shortterm and long-term outcomes. ${ }^{1}$ We can defend cost differences based on case mix and better quality but not based on inefficient, inappropriate or just more expensive practices.

Peter C. Albertsen

University of Connecticut Health Center Farmington, Connecticut

\section{REFERENCE}

1. Hu JC, Gu X, Lipsitz SR et al: Comparative effectiveness of minimally invasive vs open radical prostatectomy. JAMA 2009; $302: 1557$. 